\title{
Reading Parallel Texts in the Target Language: A Way to Improve Literary Translation Quality
}

\author{
Nazanin Shadman \\ Faculty of Foreign Languages, Kharazmi University \\ Mofatteh St. Tehran, Iran
}

Received: 05-09 - 2013

doi:10.7575/aiac.ijclts.v.1n.3p. 13
Accepted: 28-09- 2013

Published: $15-10-2013$

URL: http://dx.doi.org/10.7575/aiac.ijclts.v.1n.3p.13

\begin{abstract}
:
The present study was an attempt to investigate the effect of reading Persian literary texts on the quality of literary translations. To this end, 52 students majoring in English translation were randomly assigned to two groups. A Comprehensive English Language Test (CELT) was administered to check the homogeneity of the participants. The treatment for the experimental group consisted of reading 60 Persian short stories and poems. In the meantime, the control group went through their ordinary course curriculum. Both groups were asked to translate extracts of two short stories. The translations were then rated. Through statistical analysis, it was revealed that reading Persian literary works, indeed, improves the quality of literary translations. Therefore, to promote a more fruitful instruction on literary translation, it is suggested that translation teachers attempt to consider reading Persian literary works as part of the curriculum and ask students to read Persian texts to the extent possible, so that more qualified translations would be rendered in the area of literature.
\end{abstract}

Keywords: Parallel texts, literary translation, translation quality, translation assessment

\section{Introduction}

Nowadays, there is a consensus among scholars to take comprehensive knowledge of target language as one of the skills needed to promote translation ability. This can be traced back to the early attempts at principles of "good" translation. One of the first had been Etienne Dolet (1540/1997). He set out five principles in order of importance. The second of which is 'The translator should have a perfect knowledge of both source language and target language, so as not to lessen the majesty of the language.' Here, he stresses on knowledge of target language to produce an eloquent and natural target language form. Since those early attempts, much has been said about the necessity of mastery of the target text. In fact, creating an appropriate translation often means adapting the target text (TT) to the text-typological conventions of the target culture. Such knowledge can be gained by a comparative analysis of parallel texts, i.e. L2 and L1 texts of equal informativity which have been produced in similar communicative situations. (Schaffner, 1998c)

However, maneuvering on target language mastery in translation classes has been a somehow neglected area for educators and researchers. Most of the time, traditional teacher-based translation classes lack "a motivating component" with teachers being the absolute authority in the class. In such classes the aim is to produce an ideal translation sanctioned by the teacher. (Gonzales Davis, 2005). Professionals in the field have managed to examine a multitude of different factors and elements believed to impede or assist the formation of a "good" translation (Farahzad, 2003; Palumbo, 2009). Unfortunately, the probable effect of comprehensive knowledge of target text language of translators, professional or aspiring, involved in the task has not been adequately shed light on.

With respect to the intricate and multi-disciplinary nature of literary texts, their translation seems to be one of the, if not the most, delicate and complex challenges of any translator. The core difficulty of translations of literary works is the versatility and difference between the two at times alienated languages and cultures. The dilemma between recreation of its form or the literal translation of a literary text, along with other factors involved in delivering a literary rendering lead to the complication of literary translation (Barekat, 2005; Lambert, 2001). In this bewildering territory and amidst of so many perspectives and theories what role does mastery of the target language play in the final outcome of translation?

The present study was carried out with the hope of investigating the probability of a positive effect of the translators' knowledge of target language literature on the quality of their translation of literary texts. If there appears to be any effects at all, educators can think of ways in which they can encourage students to read literary texts of the target language with the aim of elevating the quality of their literary translations.

\subsection{Research Question}

The following question was stated to investigate the role of reading Persian literary texts on improving the quality of students' translations:

Does reading Persian literary texts improve the quality of students' translation of English literary texts? 


\section{Methodology}

\subsection{Participants}

Two intact groups with initially an aggregate of 52 male and female undergraduate students majoring in English translation at Kharazmi University provided the participants for the study. The participants all had Persian as their native language and concentrated on translating either from English into Persian or vice versa. These were students of the sixth academic semester and had already passed preliminary and rudimental courses on translation. Therefore, the researcher was insured that they were all equipped with at least the fundamental theoretical foundations and principles of translation and that they all shared almost the same level of knowledge in the field. This way, their performance in the translations they were assigned to do could not have been attributed to the lack of familiarity with the genre.

Moreover, it was ascertained that none of these participants had had any professional experience in the field of literary translation in order to remove the role their repetitious prior experience might play in determining the quality of their renderings.

In order to check the homogeneity of the participants and that they entered the experience of translation with the same level of English proficiency, a Comprehensive English Language Test (CELT) was administered. The selection of this test as a means of assuring our homogeneous subjects seemed to be appropriate, since CELT is one of the very few valid and reliable instruments not including a listening comprehension section. The evaluation of listening comprehension skill was found as irrelevant to the objectives of the researcher as it played no part in the process of translation.

After performing statistical procedures on the scores gained from CELT it was revealed that ratios of skewedness and kurtosis over their respective standard errors were within the ranges of plus and minus 1.96. Thus it was concluded that the CELT enjoys a normal distribution and that our population was of a homogeneous level of English proficiency.

Skewness $\quad-.439 / .347=-1.26$

Kurtosis $\quad-.948 / .681=-1.39$

Table 1. Descriptive statistics of CELT

\begin{tabular}{ll}
\hline Mean & 73.25 \\
\hline Median & 77 \\
\hline Mode & 77 \\
\hline Std. Deviation & 10.28 \\
\hline Variance & 105.80 \\
\hline Skewness & -.439 \\
\hline Std. Error of Skewness & .347 \\
\hline Kurtosis & -.948 \\
\hline Std. Error of Kurtosis & .681 \\
\hline Minimum & 53 \\
\hline Maximum & 89 \\
\hline
\end{tabular}

\subsection{Treatment of the experimental group}

Students in the experimental group received instruction using 60 Persian short stories and poems as the main part of their curriculum during 10 weeks. Each session the students studied Persian literary works and concentrated on how the sentences are made in Persian and what kind of phrases are used in producing literary works in Persian literature. As another part of the curriculum, they translated literary works in the class, having in mind that the Persian short stories and poems they have already read would help them come up with better translations. Furthermore, they have been asked to take the following tips into account, while translating literary texts:

1) Avoid loan words and replace them with appropriate Persian equivalents, where possible;

2) Pay careful attention to the meaning correspondence of the target text with that of the source text;

3) In case of having doubt about a Persian grammatical structure, check it with a reference on Persian grammar;

4) Make sure that the target text serves the purpose of the source text;

5) Check the fluency and logical order of sentences throughout the whole translated text;

6) Take into consideration the translation's accuracy and its meaning clarity;

7) Write concisely; process of translating;

8) Pay attention to the language order and style of the source text, and have them in mind during the

9) Be careful of connotative meanings;

10) Pay attention to the proper punctuation in both texts; 


\subsection{Treatment of the control group}

Students in the control group received instruction using traditional translation currently used in Iranian universities. In this class, no emphasis was given to reading literary works of Persian literature. Instead, each session, students translated literary texts chosen by the teacher and brought them to the class to be discussed. Students read their translations one by one and the teacher passed comments on student's translations and finally the best translation was presented by the teacher to the class. The teacher was, in fact, the absolute authority, the depository of the answers to every question and students were to memorize instances and to reproduce them.

\subsection{Material}

Upon the completion of the treatment and after reviewing and considering a number of English short stories, two stories were selected, of each an extract of almost ten lines were given to the participants in order to be translated from English into Persian. The stories were Father and I by Par Lagerkvist and The Rocking Horse Winner by D. H. Lawrence in the order of presentation. The particular extracts were chosen because they reflected a descriptive and narrative nature, believed to be more revealing of different critical factors in the participants' performances and allowing more space for technical maneuvers.

The complete stories were both read by all the students as a requirement for one of their courses and later on class discussions on different aspects of the story were debated on and personal interpretations were shared with the whole class. This was significant to the researcher since students were not just given isolated extracts of stories they had not read or been acquainted with, but pieces of stories with characterization, setting, plot and domineering mood and atmosphere of which they were all familiar. Having had previous familiarity with the stories, the students were expected to be faced with less difficulty translating them and to have a better, more accurate understanding of the mood which would enable them have a more faithful recreation of the feelings of the stories.

\subsection{Procedure}

Finally, the participants, in both groups, were asked to focus on the act of translation as an extracurricular activity at home and were provided with a sufficient amount of time to spend on the task. Knowing that their course's evaluation would not be jeopardized in the aftermath of their less than perfect translations, students could concentrate on the task away from inhibitions and negative affective factors. Moreover, allocation of sufficient time for completion of the task minimized the intimidation and pressure of the assignment, giving all students the equal chance of employing all knowledge and intuition they had at their disposal.

After the completion of the translations, 47 students ( 25 from the experimental group and 22 from the control group) who had handed their translations on both extracts were selected whose renderings were to be rated. Two raters were asked to examine the quality of the translations and to score them according to Method A of Waddington's (2001) proposed method of evaluation of translations. Both raters were experienced M.A. graduates of Translation Studies, and were believed to have an ample level of experience and mastery of theoretical foundations necessary for evaluating the translations. The method of Waddington's (2001) suggested assessment is based on the analysis and detection of errors and the criteria for its evaluation are: (1) The appropriateness of a translation regarding the comprehensibility of the source text, (2) The appropriateness of a rendering regarding factors affecting the translated text such as spelling, grammar, style, etc. and (3) The adequacy of transmission of the functions of the source text, either main or secondary.

\section{Results and Discussion}

Both raters based their evaluations of the renderings on clear objectives of the proposed assessment method. In order to avoid any inconsistencies in the criteria and the implications of personal preferences in ratings, the correlation between the two ratings was estimated. The inter-rater reliability for the two raters was calculated as $.38(\mathrm{P}=.037<.05)$. Results indicated that there was a statistically significant agreement between the two raters who rated the students' translations Afterwards, in order to probe any probable significant effect of reading Persian literary texts on the quality of literary translation, an independent t-test was run. The results of the independent t-test show that the significant index of the comparison of control group's mean scores with the experimental group's mean is $.001(\mathrm{P}=.001<.05)$ which is much lower than the 0.05 level of significance set for this study. Based on these results it can be concluded that reading target texts, indeed, affects the quality of students' renderings of literary texts. Therefore, the null hypothesis can safely be rejected. The independent sample t-test is presented in table 3.

Table 2. Experimental and control group Statistics

\begin{tabular}{rrrrr} 
& N & Mean & Std. Deviation & $\begin{array}{r}\text { Std. Error } \\
\text { Mean }\end{array}$ \\
\hline Experimental Group & 25 & 17.9200 & 1.51162 & .30232 \\
Control Group & 22 & 16.2727 & 1.73018 & .36887 \\
\hline
\end{tabular}


Table 3. Independent Sample T-Test for the comparison of the translations of Experimental and Control Groups

Levene's Test for

Equality of Variances

\begin{tabular}{|c|c|c|c|c|c|c|c|}
\hline & & $\mathrm{F}$ & Sig. & $\mathrm{t}$ & $\mathrm{df}$ & Sig. (2-tailed) & $\begin{array}{r}\text { Mean } \\
\text { Difference } \\
\end{array}$ \\
\hline \multirow[t]{2}{*}{ Grades } & $\begin{array}{r}\text { Equal variances } \\
\text { assumed }\end{array}$ & .461 & .500 & 3.484 & 45 & .001 & 1.64727 \\
\hline & $\begin{array}{r}\text { Equal variances } \\
\text { not assumed }\end{array}$ & & & 3.454 & 42.076 & .001 & 1.64727 \\
\hline
\end{tabular}

One of the expectations that Iranian university students of translation have of their academic courses is that they should be devised with their mere focus on the theory and practice of translation. Having this in mind, they find courses like translation of economic or political texts in complete congruence with their personal and academic objectives. In order to elevate their knowledge and expertise in different branches of translation, and as a part of their course requirements, these students are disposed to concentrate on theories of translation, retention of technical terms and study of translations in the field by professionals. Surprisingly, there is an apparent conversion of students' moods into rather passive and unmotivated statues when it comes to the course of literary translations. Although the number and scope of the examples of literary texts being translated into or from English during the course is very limited due to the constraints of class time, students do not seem to seek opportunities to allocate more time and energy to this particular translation genre. Students rarely engage in reading literature either in Persian or in English with the aim of effectively using their familiarity with this realm in their translations of literary texts. The problem gets more aggravated with the evident lack of enthusiasm they show during the courses on literature they have throughout their study (about 12 units). They are reluctant to actively and passionately indulge in reading literary texts, poetry in particular, having this misconception that being students of translation they do not need to study literature, neither in English, nor in Persian. Hence, whereas they willingly study and examine texts and translations of other genres, political or business for example, they are scarcely apt to approach literary texts as precious sources, laden with implicit intricacies of the art of translation.

What seems to be dismissed from their attention is the fact that most probably, the majority of the texts they will be engaged in translating of as future professional translators are literary texts. Part of the reason for this high probability of encounter with literary texts is their immense variety and innumerability. However, the students' negligence on the significance of their familiarity with literature and the establishment of a close engagement with literary texts to their career success leads to their disregarding literature courses as merely redundant and irrelative.

Knowledge of the target language is a must in producing high quality translations. However, most of the time students neglect this factor and focus on other aspects of translation. One of the reasons that students remain obdurate on their avoidance of increasing their studies in the literature of the language to which they translate, is that from the very early encounters with literature in their first language, they have developed negative feelings and attitudes towards it. To a great extent, the education system and literature teachers are to be held capable for this failure in positively creating a connection between students and literary texts from the beginning. Not only have students been trained to view literature as a subsidiary subject in comparison to other supposedly more important subjects, but also to show a subconscious intimidation when approaching it. (Khatib, 2011) As can be well expected, the problem is not diminished when students are now faced with the venture of reading literature of another culture in a foreign language.

What is obvious is the fact that familiarity with the way literary texts are produced in Persian indeed affects the quality of literary renderings. Persian literature is laden with rhetorical devices and figures of speech. Not being familiar with such devices in Persian jeopardizes the quality of literary translations. As the study indicated, there was a great improvement in the quality of the translations of the students who were trained to read literary pieces of work in their own language. Trained students were fully aware that to produce high quality translations, great consideration must be given to the style and aesthetics of the language. Most of the time trained students used the exact phrases they read during treatment sessions in their translations. However, translations of those in the control group were not indicative of any subtlety and elegance which is mostly present in literary works.

Whatever the source of these problems, it must be remembered that reformation of students' reading material and teachers' instructions is never impossible. Hence, if reading literary works of the target language is shown to have a direct effect on the quality of students' literary translations, an effort put on instilling a more welcoming enthusiasm towards reading literary works of target language seems to be a sound investment. Along educating these students on the technicalities of translation, the implementation of practical and effective methods to convince them to read literary works of their own language could greatly influence their performance on translating these texts. Being enlightened about the positive effect reading literary works of their own language could have on the outcome of their translations, students can embrace reading literary texts with less negativity.

Teachers and literature instructors can contribute to the implantation of enthusiasm towards reading literary texts of the target language in students by applying an effective methodology and the appropriate selection and introduction of materials. The literary pieces chosen should be appealing enough to create a willingness in learners to be actively 
engaged in the process of reading and therefore utmost care should be taken regarding learners' interest and expectations in this selection.

Creating an amiable ambience can help students to voice their personal interpretations of literary texts, away from anxieties of harsh and demotivating criticisms traditionally practiced in literature classes. In such an environment students become willing to amalgamate their versatile thoughts and opinions to approximate an understanding of a literary text in hand.

\section{Conclusion}

This study indicated how reading parallel texts in the target language can be useful for translating literary texts. The results drawn from the experiment show that the significant index of the comparison of control group's mean scores with the experimental group's mean is $.001(\mathrm{P}=.001<.05)$ which is much lower than the 0.05 level of significance set for this study. Students of translation can get ideas from this study to read Persian literary texts to increase the quality and speed of their literary translation. They can get information that cannot be accessed through bilingual dictionaries. Teachers of translation can use Persian literary texts to evaluate translations based on objective evidence and to design tests for their students. Researchers of translation can read Persian literary texts in order to have a quick access to a large amount of data and make the results of their studies more valid.

Unfortunately, reading literary texts in Persian don't have their proper place in current translation classes in Iran. Most of the time, during their education, students are deprived of benefits of reading literary texts on the quality of their translation and future researches. This study is hoped to be an initiative toward investing more time on instilling a more welcoming enthusiasm towards reading literary works of target language in translation classes. Along educating students on the technicalities of translation, the implementation of practical and effective methods to convince them to read literary works of their own language could greatly influence their performance on translating these texts.

\section{References}

Barekat, B. (2005). Literary Translation as L'Ecriture. In Translation Studies Quarterly, Vol. 3, No. 10. PP. 55-63.

Dolet, E. (1540/1997) La maniere de bien traduire d'une langue en aultre, Paris: J. de Marnef, translated by D. G. Ross as 'How to translate well from one language into another', in D. Robinson (ed.) (1997b), pp. 95-7.

Farahzad, F. (2003). A Theoretical Framework for Translation Studies. In Translation Studies Quarterly, Vol. 1, No. 3, pp 29-36.

Gonzalez Davis, M. (2005). Minding the process, improving the product: Alternatives to traditional translator training. In Tennent, M. (Ed.) Training for the New Millenium. Amsterdam and Philadelphia: John Benjamins, pp. 67-83.

Khatib, S. (2011), The Relationship of Attitude towards Literature and the Quality of Literary Translation. In Translation Studies Quarterly, Vol. 9, No. 34, p. 63.

Lambert, J. (1998). Literary Translation: Research Issues. In Baker, M. (2001). Routledge Encyclopedia of Translation Studies. NY: Routledge.

Palumbo, G. (2009). Key Terms in Translation Studies. London: Continuum International Publishing Group.

Robinson, D. (ed.) (1997b) Western Translation theory from Herodotus to Nietzche, Manchester: St Jerome.

Schaffner, Christina (1998c) Parallel texts in translation. In L.Bowker, M. Cronin, D. Kenny and J. Pearson (eds) Unity in Diversity? Current Trends in Translation Studies. Manchester: St. Jerome.

Waddington, C. (2001). Different Methods of Evaluating Student Translations: The Question of Validity. In Translation Studies Quarterly, Vol. 3, No. 10, pp. 27-40.

Williams, J. \& Chesterman, A. (2002). The Map: A Beginner's Guide to Doing Research in Translation Studies.

Manchester: St. Jerome Publishing. 